\title{
Ecological aspects of the world food security
}

\author{
Lyudmila Kopteva ${ }^{1, *}$, Lyudmila Shabalina ${ }^{2}$ and Elena Kashirina ${ }^{3}$ \\ ${ }^{1}$ St. Petersburg Branch Russian Customs Academy, Sofijskaya, 52, lit. A, 1912236, Saint-Petersburg, \\ Russia \\ ${ }^{2}$ Donetsk National Technical University, Artema str., 58, 83000, Donetsk, Ukraine \\ ${ }^{3}$ Kuban State Technological University, Moskovskaya street, 2, 350072, Krasnodar, Russia
}

\begin{abstract}
The article identifies the main environmental factors affecting food security, based on the development trend of the main indicators of food security in the world. It is revealed that in the future, the impact of new technologies and climate change will become more important. The article defines a solution to the problem of world food security, which requires the cooperation of both the world community and international organizations.
\end{abstract}

\section{Introduction}

Awareness of the current environmental situation and the accumulation of evidence of the adverse effects of human activity on the environment and human health created prerequisites for a deeper understanding of the relationship between natural conditions and health of population: its nutrition, health status, working capacity and longevity depend on the quality of air, soil, plants and animals. In other words, the soil, food, balanced ecosystems, which have long been ensured in many developed countries by a sharp decline, in particular, of the use of mineral fertilizers and the complete abandonment of toxic chemicals (most of which are carcinogenic), are essentially the basis of health, the provision of which is unthinkable without scientifically grounded environmental management and ecologization of the agrarian sector of the economy [1]. The worsening environmental situation throughout the world causes enormous damage to almost all areas of the economy, which ultimately affects food production. Irreplaceable damage to food production, with grave consequences for the future generation, are factors that have been disturbing the natural circulation of the Earth's vegetation cover, that is, deforestation, artificial disruption of river and groundwater balances, the rapid growth of world population and, of course, irresponsible interference into natural processes. These are just some of the factors affecting ecologically clean food production, negatively impacting world food security. The real threat today is the loss of significant areas of arable land due to their salinization and waterlogging. The great concern is the destruction of the ozone layer of the planet stratosphere and the consequences of increasing ultraviolet radiation. All these consequences will not only be detrimental, but also have prolonged in time cumulative effect [2]. In 2015, the United Nations Organization adopted the resolution "Transforming our world: the 2030 Agenda for Sustainable Development", which set

\footnotetext{
*Corresponding author: lusis63@mail.ru
} 
seventeen global goals for the sustainable development of the world, one of which is to eliminate world hunger, ensure food security and improving nutrition as well as promoting sustainable agriculture [3].

According to experts, global food and feedstuff demand will increase in the first half of the XXIst century, while crops will increasingly be used for bioenergy production and other industrial purposes, which will threaten the food security of the least developed and developing countries. In 2016, hunger prevalence rate decreased by seven percentage points in the world, amounting to $11 \%$, compared to the early $1990 \mathrm{~s}$. At the same time, in developing countries this figure decreased from 23 to $13 \%$, which is due to the economic policies of the states, as well as the activities of international organizations aimed at fighting hunger. Due to the increase in the world's population from 5 to 7 billion, the absolute value of the hungry still varies in the range of about 800 million people, which makes it necessary to consider the factors affecting world food security [4].

\section{Background}

The environmental factors that affect the specifics of the world food market, were studied by E. Kazantseva, E. Kolesnikova, A. Melnikova and others. A. Kaygorodtsev, V. Maksakovsky and K. Martynov considered the global problem of food safety. L. Falvey, R. Munang, M. Rivington, R. Richardson studied the influence of food production on the ecological system. The regulation and control of world food security is carried out by various international organizations. Thus, assisting developing countries in improving agricultural efficiency and ensuring healthy nutrition is performed by the Food and Agriculture Organization of the United Nations (FAO), the adoption of policy decisions in the field of sustainable food safety creation is conducted by the International Food Policy Research Institute (IFPRI), the allocation of financial resources to increase food production and improve the nutrition situation for poor groups is run by International Fund for Agricultural Development (IFAD).

The main purpose of the research is identification of the environmental factors affecting world food security.

\section{Statement of basic material}

The protracted global financial crisis, which began in 2008, negatively impacts global food production. So, for the period of 2012-2016 the food security index of most developing countries declined by an average of 2 points [5]. Food security is an integral part of the sustainable world development, therefore it is necessary to ensure a balance in the production and consumption of food, which depends on many different factors. Consider the main ones.

1. Population growth. The annual growth of world population declined from $2.2 \%$ in the 1960 s up to $1.1 \%$ in 2017 [1]. Thus, according to experts, with the continuation of this trend, the world population in 2050 will amount to 9.7 billion people, while more than half of the expected growth will occur in Africa, where the population will increase from 1.2 to 2.6 billion people, which will complicate the solution of poverty and hunger problem. During this period, in Asia, population growth is expected to be at the level of $20 \%$, in South America up to $30 \%$, in Europe a decline of 3\% is projected. However, according to experts, with increased migration to European countries, the population by 2050 may remain at the 2010 level (Fig. 1). 


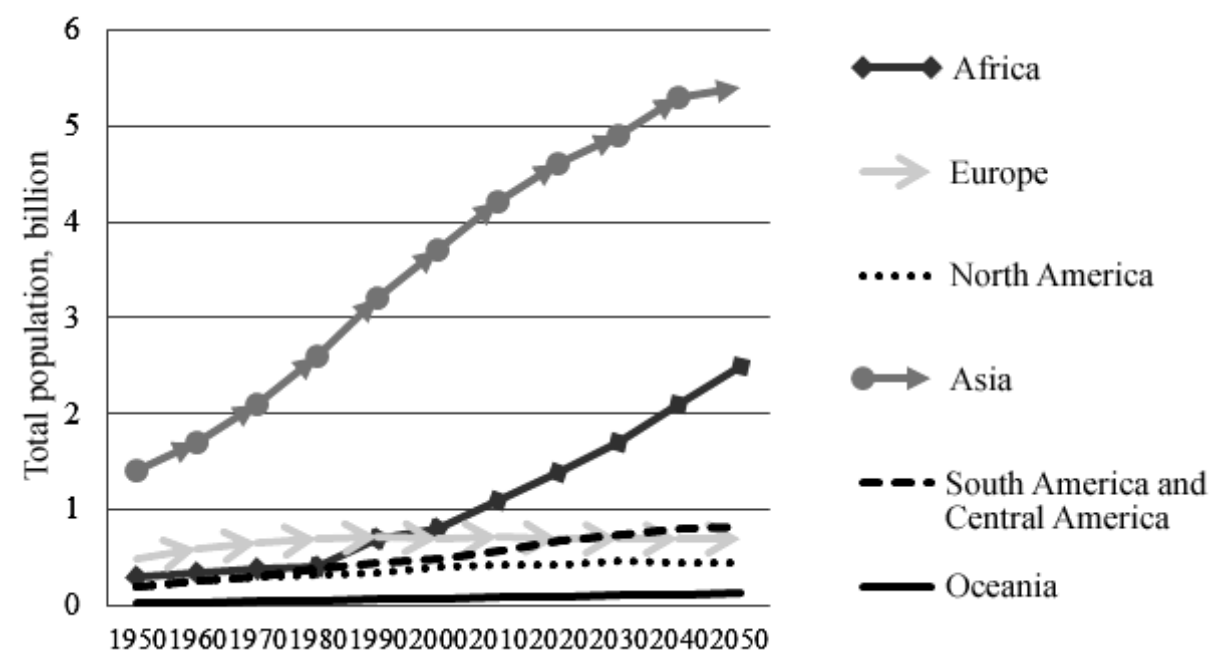

Fig. 1. World population by regions (compiled by the authors based on [1]. Data for 2020-2050 are predictive).

2. The average life expectancy of the population. In the world, this figure increased from 67 years in 2010 to 70 years in 2017, while the greatest increase was observed in Africa, where life expectancy increased by 6 years, reaching 61 years, which was largely due to improved food provision and access to medical care [3].

3. Volatility of global food prices. The period from 1999 to 2006 , characterized by low prices, was replaced by a long period of high and volatile prices in 2007-2013 due to the global crisis. In 2014, markets stabilized and returned to low prices. For example, from 2012 to 2017 grain prices fell by $44 \%$, while for agricultural products as a whole declined overall by $21 \%$. According to experts, by 2025 prices for agricultural products are expected to fall, which will positively affect global food security $[3,8]$.

4. Increasing crop cultivation for biofuel production. This trend has led to a reduction in food crops cultivation. For example, from 2007 to 2016 the quantity of areas with biofuel crops has been enlarged, which increased production from 54 billion to 137 billion liters biofuels in the world. In Europe, food crops are being supplanted by pharmaceutical crops, which are more expensive in comparison with food crops [7].

5. Urbanization. Experts predict that in 2030 the urban population will prevail in all regions of the world, and by 2050 its number will reach 6.3 billion people. At the same time, the number of the rural population will decrease and will amount to 3.4 billion people, which will negatively affect the food situation in the world [4].

6. The income level of the population. According to experts, income growth in developing countries will lead to a change in the structure of food consumption. For example, consumption of fruits and vegetables, as well as products of animal origin will increase, which will lead to the need for more intensive production of these products, as well as improving the quality of nutrition in these countries. Thus, the indicator of the number of calories consumed per capita from 2002 to 2014 increased in developing countries by $9.5 \%$, in the least developed by $8.1 \%$ and in developed by $1.8 \%$. According to FAO experts, by 2024 the amount of per capita consumption will increase by approximately the same percentage for each group of countries [4.8].

7. Reducing consumer food waste. The global quantitative loss of food products and waste per year is about $30 \%$ for grain crops, $40-50 \%$ for fruits and vegetables, $20 \%$ for meat and dairy products, and also $35 \%$ for fish. Per capita consumer waste is $95-115 \mathrm{~kg}$ per year in Europe and North America, while in Africa and Asia it is 6-11 kg. Experts predict 
that by 2030 there will be a decrease in food waste by half, reaching 650 million tons per year [4].

8. Climate change. At the global level, positive and negative forecasts of the effects on crop yields in different regions of the world in the period up to 2030 balance each other, as in some regions of the world there will be an increase in yields due to climate change, and in others - a decrease. After 2030, the balance will become increasingly negative, as the Intergovernmental Panel on Climate Change (IPCC) projects that the decline in crop yields by 2050 could be $10-25 \%$ [4].

9. Growth in the production of aquaculture food and industrial fishing. The rapidly growing population put considerable pressure on the fish resources of the seas and oceans. In order to provide the population with fish, in addition to fishing, its artificial cultivation began, as a result of which the growth rate of world trade in fish intended for human consumption was ahead of the population growth rate. So, from 1970 to 2017 an average growth rate is $3.2 \%$ compared with $1.6 \%$ of the world population growth. The availability of fish per capita increased from $9.9 \mathrm{~kg}$ in the $1960 \mathrm{~s}$ up to $14.4 \mathrm{~kg}$ in the $1990 \mathrm{~s}$ and $20 \mathrm{~kg}$ in 2017. According to experts, the volume of aquaculture products by 2025 will exceed the volume of fish obtained in natural conditions and by 2050 will become the main source of fish products [4].

10. The enlargement of cultivated agricultural areas. Thus, on average, in all regions of the world, the amount of agricultural land increased by 7\% in 2017 compared to the 1990s. For example, in Africa this figure increased by 35\%, in South America - by $40 \%$, in Asia - by $20 \%$. Experts predict that, on average, the world will increase the cultivated area by $6 \%$ over the period 2015-2050, while in Africa it will be $30 \%$ due to new technologies for growing crops in arid regions. Whereas in Europe the area under cultivation will decrease by an average of $45 \%$, since unproductive land is gradually being withdrawn from agricultural land use and used for construction or afforestation. (table 1).

Table 1. Size of cultivated area in agriculture, million hectares.

\begin{tabular}{|l|r|r|r|r|r|r|r|r|r|}
\hline Regions & 1980 & 1990 & 2000 & 2010 & 2015 & 2020 & 2030 & 2040 & 2050 \\
\hline World & 1453 & 1520.8 & 1514.3 & 1541.1 & 1553 & 1571.8 & 1597.5 & 1623.3 & 1649.1 \\
\hline Africa & 190.5 & 203.6 & 221.9 & 256.4 & 258.3 & 272.1 & 293.7 & 315.3 & 336.9 \\
\hline America & 383.5 & 389.8 & 391.9 & 395.4 & 398.7 & 399.6 & 403.4 & 407.2 & 410.9 \\
\hline Asia & 458.5 & 507.6 & 545.6 & 553.4 & 553.6 & 583.9 & 605.4 & 627.0 & 648.6 \\
\hline Europe & 372.4 & 367.6 & 304.4 & 290.7 & 292.1 & 256.7 & 225.9 & 195.0 & 164.2 \\
\hline Australia & 44.2 & 48.1 & 47.6 & 43.0 & 48.1 & 44.7 & 44.3 & 43.9 & 43.5 \\
\hline
\end{tabular}

*Note: compiled by the authors based on [10].

11. Production and consumption of grain. On average, the growth rate of grain production in the world corresponded to the growth rate of the population from 1980 to 2017. For example, in Asia, the growth of grain production was $3.4 \%$, while in North America - 1.7\%, Europe - 1.4\%. According to experts forecast, in Africa grain production will increase by $83 \%$ from 2018 to 2050 , while in Europe there will be a $21 \%$ reduction in grain production, which is associated with a decrease in the area of arable land and the substitution of food crops by biofuel and pharmaceutical crops (fig.2). 


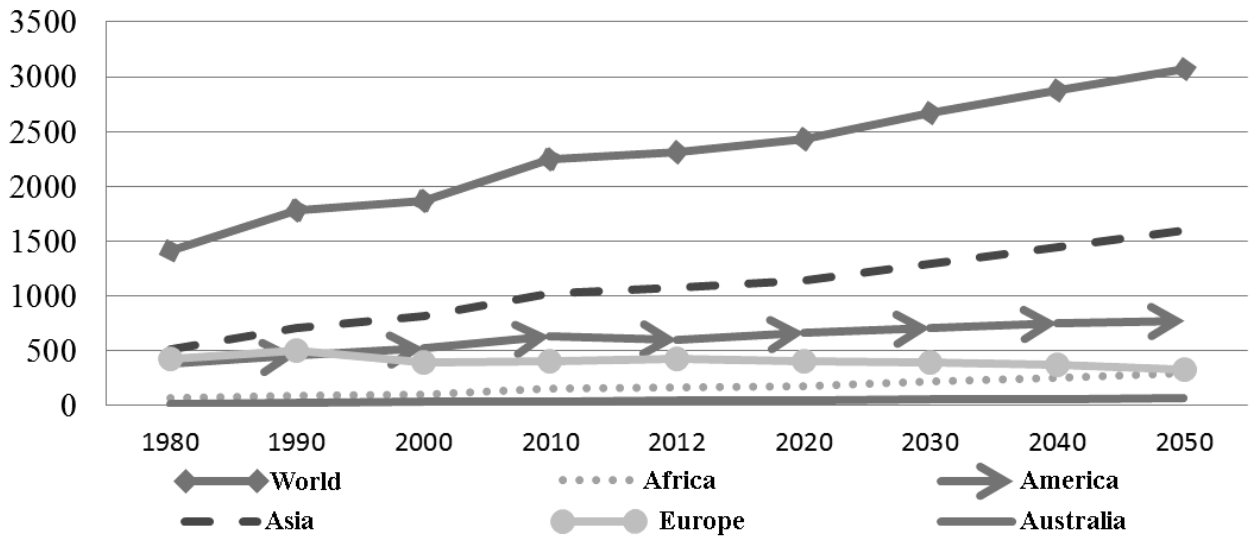

Fig. 2. Grain production in the world, million tons (compiled by the authors based on [10]).

Food consumption of grain per capita in the world from 1980 to 2017 practically did not change, reaching $146.7 \mathrm{~kg}$, while in Africa the consumption of these crops from 1980 to 2010 increased more than twice, reaching 141 million tons, while in America - by 67\%. At the same time, in Europe, consumption decreased by $12 \%$, due to a decrease in population. By 2050 , grain consumption in the world will increase at a steady pace, the largest increase will occur in regions with high population growth rates - Africa and Asia, where the growth rate will be 200 and $50 \%$ respectively, while in Europe there will be a decrease of $24 \%$ (table 2).

Table 2. Food consumption of grain crops in the world, million tons.

\begin{tabular}{|l|r|r|r|r|r|r|r|r|}
\hline Regions & \multicolumn{1}{|c|}{1980} & \multicolumn{1}{c|}{1990} & \multicolumn{1}{c|}{2000} & \multicolumn{1}{c|}{2010} & \multicolumn{1}{c|}{2020} & \multicolumn{1}{c|}{2030} & \multicolumn{1}{c|}{2040} & \multicolumn{1}{c|}{2050} \\
\hline World & 628.1 & 783.4 & 890.4 & 976.7 & 1182.7 & 1326.3 & 1457.8 & 1576.7 \\
\hline Africa & 62.8 & 85.8 & 110.8 & 141.0 & 203.8 & 261.0 & 327.9 & 403.0 \\
\hline America & 66.3 & 83.8 & 100.3 & 110.4 & 131.0 & 145.9 & 158.8 & 169.6 \\
\hline Asia & 389.3 & 503.2 & 582.7 & 626.4 & 752.9 & 828.4 & 884.7 & 922.3 \\
\hline Europe & 108.4 & 109.2 & 95.0 & 96.7 & 92.4 & 87.9 & 82.9 & 77.7 \\
\hline Australia & 1.4 & 1.5 & 1.6 & 2.1 & 2.7 & 3.1 & 3.6 & 4.1 \\
\hline
\end{tabular}

*Note: compiled by the authors based on [10].

The foreign trade balance of grains in Asia amounted to (-) 95 million tons in 2010, however, by 2050, imports will decrease to 37.8 million tons, which is connected with an increase in cereal production in Asia. America, Europe and Australia will retain their positions and remain world grain exporters. The largest increase in grain surplus will be demonstrated by Europe, which will be connected with a decrease in grain consumption in the region due to a reduction in the number of population. Despite the fact that by 2050 in Africa an increase in cereal production is expected - an average of $1.62 \%$ per year, an increase in the number of inhabitants and an increase in per capita consumption will lead to a grain deficit in the region to (-) 197 million tons. Africa will not get rid of the dependence of grain imports, despite the pace of areas expansion and the use of new technologies, which will aggravate the situation in the domestic market.

12. Production and consumption of meat. In 2017, more than $40 \%$ of world meat production was generated in Asia, while in 1980 this region produced only $20 \%$. In Africa, 
meat production also increased during this period, but consumption remained at $16 \mathrm{~kg}$ per capita, which did not lead to full satisfaction of demand and, according to experts, this tendency will continue in the region in the future. America, Australia and Europe will remain the main exporters of meat, where the rate of increase in meat production will be kept at a stable level until 2050, while Asia will increase meat production to $45 \%$ of total production and will amount to 251.2 million tons (fig.3).

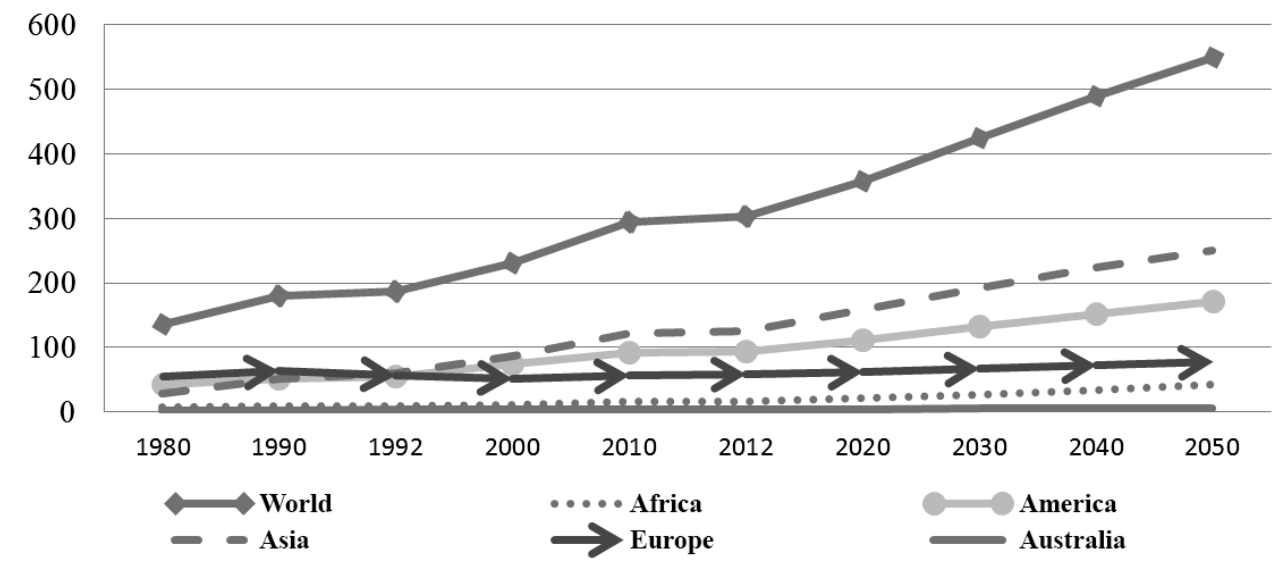

Fig. 3. Meat production in the world, million tons (compiled by the authors based on [10]).

The aggregate meat consumption in the world will almost double by 2050, to 544 million tons, compared with 278.9 million tons in 2010. In Asian countries, where, on average, total consumption more than quadrupled in 1980-2010, it will double by 2050 . In Africa, consumption will more than triple by 2050 from 16.4 to 50 million tons (table 3). At the same time, meat consumption in America, Europe and Australia will increase at a steady pace.

Table 3.Consumption of meat in the world, million tons.

\begin{tabular}{|c|c|c|c|c|c|c|c|c|}
\hline Regions & 1980 & 1990 & 2000 & 2010 & 2020 & 2030 & 2040 & 2050 \\
\hline World & 134.0 & 175.7 & 229.4 & 278.9 & 350.2 & 424.8 & 489.1 & 544.0 \\
\hline Africa & 6.7 & 8.9 & 11.7 & 16.4 & 23.6 & 31.0 & 39.8 & 50.0 \\
\hline America & 38.4 & 45.2 & 61.1 & 68.7 & 82.0 & 94.0 & 105.7 & 116.8 \\
\hline Asia & 29.0 & 52.0 & 95.5 & 124.5 & 160.4 & 193 & 226.1 & 255.6 \\
\hline Europe & 54.3 & 62.8 & 51.1 & 56.3 & 61.5 & 66.7 & 71.9 & 77.1 \\
\hline Australia & 1.6 & 1.9 & 2.1 & 2.4 & 2.8 & 3.2 & 3.5 & 3.8 \\
\hline
\end{tabular}

*Note: compiled by authors based on [10].

In the period up to 2050, the balance of foreign trade in meat products in America will be positive, amounting to 54.2 million tons. The shortage of meat, which will occur in Africa and Asia, can be resolved through trade flows from America, where there will be the largest surplus of meat products.

13. New technologies. For example, in 2013, one kilogram of meat grown in the laboratory cost 3 million US Dollars, however, modern technologies in 2018 allowed it to be created for 100 US Dollars. 
In the future, the problem of hunger will be partially solved by genetic engineering aimed at modifying the seeds of grain crops so that they can be grown in arid conditions. Similar studies are already being conducted in China and the United States. In the future, food security will be also provided by satellite monitoring of crops and precision farming $[4,9]$.

The above problems determine the need to reduce environmental threats by regulating them, which may include cyclical processes of analytical work to assess the results of possible risk manifestations and the choice of procedures (methods) of regulation according to the following methodology [10]:

- assessment of the possible impact of environmental threats on global economic security (range of magnitude and probability of occurrence);

- making decisions regarding the feasible level of impact of environmental threats factors on the world economy;

- development of a new method of regulation, if the threats exceed the permissible level;

- assessment of the effectiveness of the procedure of regulating environmental threats and their influence on ensuring global economic security.

The methods of regulation of agroecology include:

- avoidance of risk (prevention) by choosing a strategic decision not to start or not to continue activities leading to an unacceptable level of environmental threats;

- elimination of the factor (source) of the formation of environmental threats;

- change in the probability of realization (manifestation) of threats;

- changing the interval of magnitude (result) of the possible manifestation of threats;

- diversification - distribution of threats by the other party or parties (including sources of resources, activities, production line, consumers, organizational and legal forms, etc.).

The ability of the world's economies to respond to the application of environmental instruments used in the WTO system, and, by regulating, to reduce threats, takes on the character not only of protecting its own citizens, their health and life, animals, plants, and natural resources, but also protecting national economic interests, ensuring proper level of international environmental requirements for production [11].

\section{Conclusion}

The main ecological aspects affecting world food security have been identified in the article. According to experts by 2050, new technologies and climate change will become increasingly important. To ensure world food security, innovative systems that preserve and strengthen natural resources, while increasing productivity, will be required. There is a need for transformations aimed at the formation of integrated approaches, such as agroecology, climate-optimized farming, soil protection and resource-saving agriculture. Greater international cooperation, adaptation strategies and policy responses to global change will be needed, including management options for water distribution, land use schemes, food trade, post-harvest food processing and foodstuff prices. Developed countries and international organizations need to provide financial and food assistance to the least developed and developing countries, since only such cooperation will ensure world food security.

\section{References}

1. R. Munang, I. Thiaw, K. Alverson, M. Mumba, J. Liu, M. Rivington, Current Opinion in Environmental. Sustainability 5, 67-71 (2013)

2. L. Falvey, Asian Journal of Agriculture and Development 1(2), 1-16 (2018) 
3. G. Dyakova, S. Izmaylova, A. Mottaeva, E. Karanina, IOP Conf. Series: Earth and Environmental Science 90, 012218 (2017) doi :10.1088/1755-1315/90/1/012218

4. K. Kunanbayeva, A.Gorovoy, A. Butyrin, MATEC Web of Conferences 193, 05048 (2018)

5. Y. Morozyuk, A. Sharkova, I. Merkulina, O. Vasilyeva, Journal of Environmental Management and Tourism 8 (3-19), 507-515 (2017)

6. L. Shabalina, A. Kapko, Quarterly scientific journal «Economic Herald of the Donbas» 4(46), 28-34 (2016)

7. S. Rinaldi, M. Pasetti, M. Trioni, G. Vivacqua, IEEE International Instrumentation and Measurement Technology Conference (I2MTC) (2017). DOI: 10.1109/I2MTC.2017.7969756

8. L. Kopteva, L. Shabalina and A.Prorokov, MATEC Web of Conferences 170, 01054 (2018)

9. M. Pasetti, S. Rinaldi, D. Manerba, Appl Sci-Basel, 8, 3 (2018), 432. DOI: 10.3390/app8030432

10. A.V. Akimov, M.G. Borisov, I.V. Deryugina, V.G. Kandalintsev, Eastern countries by 2050: population, energy, food, investment climate (Institute of Oriental Studies RAS, Moscow, 2017)

11. V.I. Avdiyskiy, V.M. Bezdenezhnyih, V.K. Senchagova, Unified national standards to ensure the economic security of the business entities of the Russian Federation (St. Petersburg, 2014) 